\title{
Sistem Pemantauan Ruangan Dengan Server Raspberry Pi
}

\author{
Egrit Nurcahyo Wijatsongko*1, Agfianto Eko Putra ${ }^{2}$, Bambang Nurcahyo Prastowo ${ }^{3}$ \\ ${ }^{1}$ Prodi Elektronika dan Instrumentasi, FMIPA, UGM Yogyakarta \\ 2,3 Jurusan Ilmu Komputer dan Elektronika, FMIPA UGM, Yogyakarta

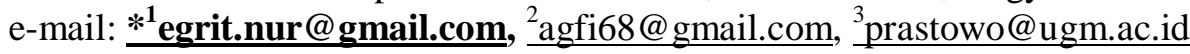

\begin{abstract}
Abstrak
Pemantauan secara terus menerus akan membebani storage pada server, karena ukuran berkas video hasil rekaman akan sangat besar. Salah satu cara untuk mengatasi masalah tersebut adalah dengan membuat agar webcam hanya merekam pada saat-saat dibutuhkan saja. Contoh 'saat yang dibutuhkan' ini adalah saat seseorang memasuki ruangan. Karena itu dibutuhkan sebuah sistem pemantauan yang dapat melakukan deteksi gerakan pada suatu ruangan.

Dalam penelitian ini, masalah tersebut coba diselesaikan dengan merancang bangun sistem pemantau ruangan berbasis Komputer mini (Raspberry Pi). Sistem pemantauan ini dibuat menggunakan program motion. Program motion menangani deteksi gerak dan streaming, selain itu sistem juga dibuat agar dapat mengirimkan notifikasi saat terjadi gerakan melalui email. Untuk alasan keamanan dan backup data, sistem juga akan mengunggah video hasil rekaman ke Google Drive. Sistem terdiri dari 1 server dan 1 klien yang saling berhubungan menggunakan jaringan WLAN.

Sistem diuji kinerjanya dengan mengamati parameter frame rate video hasil rekaman. Sistem juga diuji kemampuan deteksi geraknya pada intensitas cahaya yang berbeda-beda. Dari pengujian didapatkan bahwa kondisi terbaik untuk sistem adalah pada framesize 320x240 dengan intensitas cahaya lebih dari 8 lux.
\end{abstract}

Kata kunci-Motion, deteksi gerak, Raspberry Pi, email, Google Drive

\begin{abstract}
Continuous record will overload storage, due to big size recorded video files. One of the solution to this problem is to make system only record at necessary time. The example of the "necessary time" is when someone enter the room. Because of that, surveillance system which can detect motion in the room is needed.

In this research, mentioned problem was tried to be solved by design and build a mini computer (Raspberry Pi) based room surveillance system. This surveillance system is made with Motion program. Motion program handle motion detection and streaming. Besides that, system also made so it can send notification via email, when motion is detected. For security and back up data reasons, system will also upload recorded video to Google Drive. System consists of one server and one client that are connected using WLAN network.

The System performance was tested by observing recorded video frame rates as parameter. The motion detection of the system was also tested on various light intensity. From the test, got that the best condition for the system is at frame size 320x240 with light intensity more than 8 lux.
\end{abstract}

Keywords - Motion, motion detection, Raspberry Pi, email, Google Drive 


\section{PENDAHULUAN}

$\mathrm{P}$ emantauan secara terus menerus seperti pada CCTV dipusat perbelanjaan atau perkantoran, akan membebani storage pada server, karena ukuran file video hasil rekaman akan sangat besar. Salah satu cara untuk mengatasi masalah tersebut dengan membuat agar webcam hanya merekam pada saat-saat yang dibutuhkan saja. Salah satu contoh 'saat yang dibutuhkan' ini adalah saat seseorang memasuki ruangan. Karena itu dibutuhkan sebuah sistem pemantauan yang dapat melakukan deteksi gerakan pada suatu ruangan.

Oleh karena itu untuk membuat sistem pengawasan tersebut dibutuhkan sebuah server yang dapat melakukan pengolahan data video digital sekaligus mengirimkan peringatan ke email pemilik. Untuk memenuhi kebutuhan tersebut bisa digunakan Single Board Computer (SBC) sebagai server dari sistem pemantauan tersebut. Salah satu contoh SBC yang dapat digunakan untuk membangun sistem pemantauan ini adalah Raspberry pi. Penelitian ini berbeda dengan penelitian sebelumnya dari sisi hardwarenya, penelitian sebelumnya yang sejenis menggunakan PC sebagai server sistem pemantauannya[1]. Selain PC penelitian lain menggunakan mini PC, sebagai server, salah satu contoh mini pc yang digunakan adalah Mini PC Zotac Zbox Nano AD10[2].

\section{METODE PENELITIAN}

\subsection{Rancangan Penelitian}

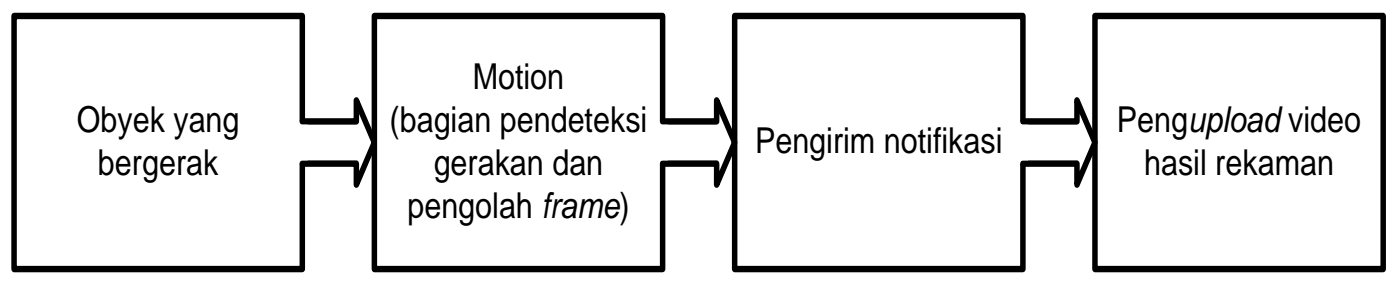

Gambar 1 Diagram blok sistem untuk pendeteksian gerak

Sinyal video akan diproses di Raspberry $\mathrm{Pi}$, gerakan pada video dideteksi dengan program bernama Motion[3], Motion mendeteksi gerakan dengan memantau sinyal video dari satu atau lebih kamera dan dapat mengetahui jika suatu bagian dari gambar telah berubah. Motion juga digunakan untuk menampilkan video streaming di web browser, atau media player yang mendukung video streaming. Seperti yang ditunjukkan pada Gambar 1, setelah terdeteksi gerakan maka sistem akan mengambil citra dan mengirimnya bersama notifikasi ke email pengguna. Lalu sistem merekam kondisi ruangan hingga tidak terdeteksi gerakan, setelah selesai merekam maka sistem akan mengunggah video tersebut ke Google Drive agar dapat diakses kembali sewaktu-waktu. Setelah selesai mengunggah, maka file video dalam storage Raspberry Pi akan segera dihapus agar tidak menumpuk di storage.

Perangkat keras yang dipakai dalam sistem ini berupa webcam, dan single board computer Raspberry Pi sebagai server, serta 1 unit PC sebagai klien. Webcam yang digunakan adalah Logitech C170 yang memiliki kualitas video maksimal $30 \mathrm{fps}$. Single board computer yang digunakan adalah Raspberry pi model B rev 1, komunikasi antara Raspberry pi (server) ke unit PC (klien) menggunakan WLAN. Webcam menangkap Gambar yang akan diproses oleh motion, dan dikirim ke klien melalui Wi-Fi dongle yang sudah menghubungkan Raspberry Pi dengan klien. Skema Rancangan perangkat keras tersebut ditunjukkan pada Gambar 2.

IJEIS Vol. 5, No. 1, April $2015: 65-76$ 


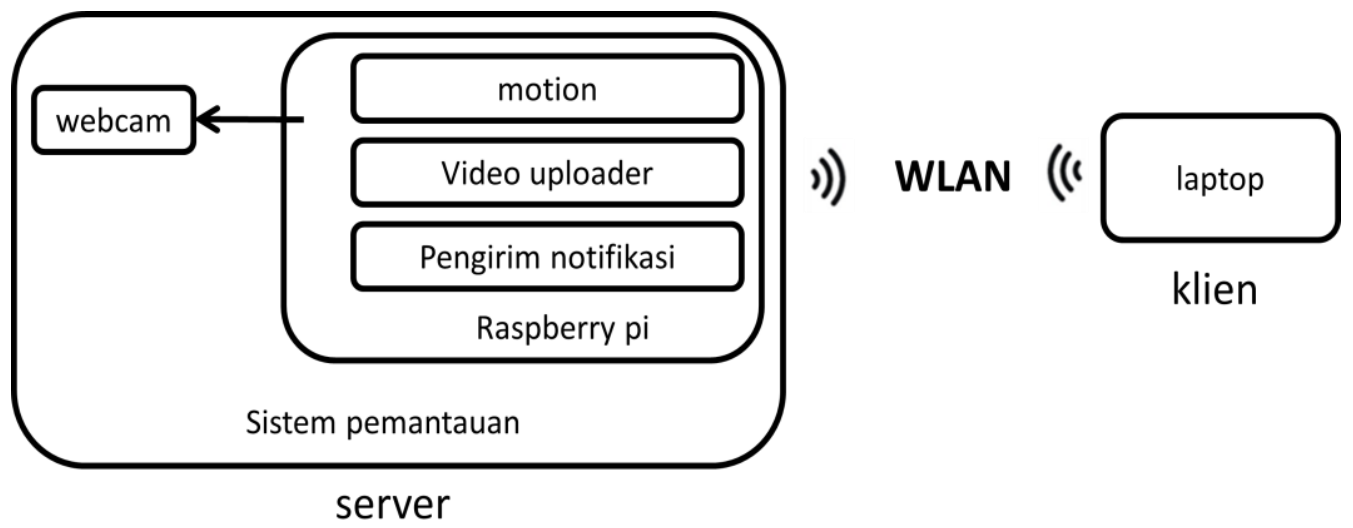

Gambar 2 Rancangan perangkat keras secara keseluruhan

\section{2 Implementasi Software}

Rancangan perangkat lunak dalam sistem ini ada dua bagian, yang pertama bagian sistem monitoring yang terdapat di dalam server Rapsberry Pi, disini terjadi pengolahan sinyal video untuk mendeteksi gerakan, juga pemberian notifikasi ke pengguna. Yang kedua, bagian video streaming, ini adalah bagian dimana dilakukan pengolahan sinyal yang dikirim oleh server agar bisa ditampilkan di web browser, keduanya tergabung dalam satu sistem. Salah satu sistem operasi yang dapat digunakan di raspberry pi adalah sistem operasi Occidentalis 2.0 yang digunakan dalam penelitian ini. Occidentalis 2.0 berbasis Linux debian, Occidentalis sendiri merupakan modifikasi dari sistem operasi Raspbian, Linux Debian yang ditujukan untuk Raspberry pi, modifikasi dilakukan sehingga Occidentalis menjadi versi ringan dari Raspbian.

\section{2.1Pendeteksian Gerakan Pada Motion}

Gerakan pada video dideteksi oleh Motion dengan membandingkan frame acuan dan frame baru, jika terjadi perubahan yang melebihi threshold yang ditentukan, maka dapat disimpulkan terdapat gerakan yang tertangkap video. Secara default, threshold yang digunakan Motion adalah 1500 pixel, artinya perubahan pixel yang terjadi harus melebihi 1500 pixel agar dapat dideteksi sebagai gerakan. Pengiriman notifikasi dilakukan oleh program lain yang eksekusi nya dikendalikan oleh Motion, misalnya saat Motion mendeteksi gerakan maka motion juga akan memberi perintah kepada program lain untuk mengirimkan notifikasi, saat sudah selesai merekam, program lain akan tereksekusi untuk mengunggah video tersebut ke Google drive.

\section{2. 2 Video streaming}

Untuk menampilkan video streaming pada web browser, digunakan program Motion, Motion menggunakan pemrograman berbasis protokol web untuk melakukan video streaming. Video stream yang dihasilkan Motion berformat mjpeg, atau motion jpeg, artinya video stream yang dihasilkan Motion sebenarnya adalah citra JPG yang di stream melalui protocol HTTP[4]. Untuk menampilkan video streaming pengguna cukup mengubah konfigurasi yang sudah disiapkan Motion. Pengguna cukup mengeset port yang akan digunakan untuk menampilkan video streaming, setelah itu tinggal menuliskannya pada web browser. Alamat web yang dituliskan berupa port yang sudah dialokasikan untuk webcam, contoh http://192.168.0.110:8081 dimana 192.168.0.110 adalah alamat ip dari server (Raspberry pi) sedangkan 8081 adalah adalah port yang sudah kita sediakan untuk webcam.

\section{2.3 Implementasi Pemberi Notifikasi}

Notifikasi diberikan oleh sistem ke pengguna atau klien melalui email, email yang digunakan adalah layanan email milik Google yaitu Gmail. Notifikasi yang dikirimkan berupa pemberitahuan bahwa terdekteksi gerakan di tempat yang diawasi, disertai dengan citra yang 
ditangkap saat terdeteksi gerakan, citra ini dikirimkan sebagai lampiran pada email notifikasi, namuncitra tersebut sebelumnya harus diubah ke format base 64 agar dapat dikirimkan sebagai attachment melalui email. Meng-encode ke base64 berarti mengubah file binary menjadi ASCII, sehingga dapat dibaca oleh email. Email dikirimkan melalui protokol SMTP[5].

\section{2.4 Implementasi Pengupload video}

Saat terdeteksi gerakan motion akan mulai merekam hingga tidak terdeteksi gerakan selama waktu yang ditentukan. Hasil rekaman tersebut akan diupload ke Google Drive oleh sistem. Hal ini dilakukan dengan alasan keamanan dan backup data, semisal ruangan yang diawasi dimasuki oleh pencuri, kemudian pencuri menyadari dirinya telah direkam dan merusak sistem. Pengguna masih memiliki bukti berupa video yang tersimpan di Google drive. Penguploadan video dilakukan dengan API (Application programming interface) yang sudah disediakan Google untuk Google Drive.

\subsection{Implementasi Hardware}

Raspberry PI sebagai server bertugas untuk merekam gambar dengan webcam, untuk kemudian dikirimkan dengan komunikasi WLAN sebagai video streaming ke laptop klien dengan bantuan program Motion yang sudah di installkan di server. Raspberry pi dan laptop klien sama-sama menggunakan wireless adapter yang terintegrasi 802.11n. Pada Gambar 3 diperlihatkan gambar keseluruhan perangkat keras untuk server.

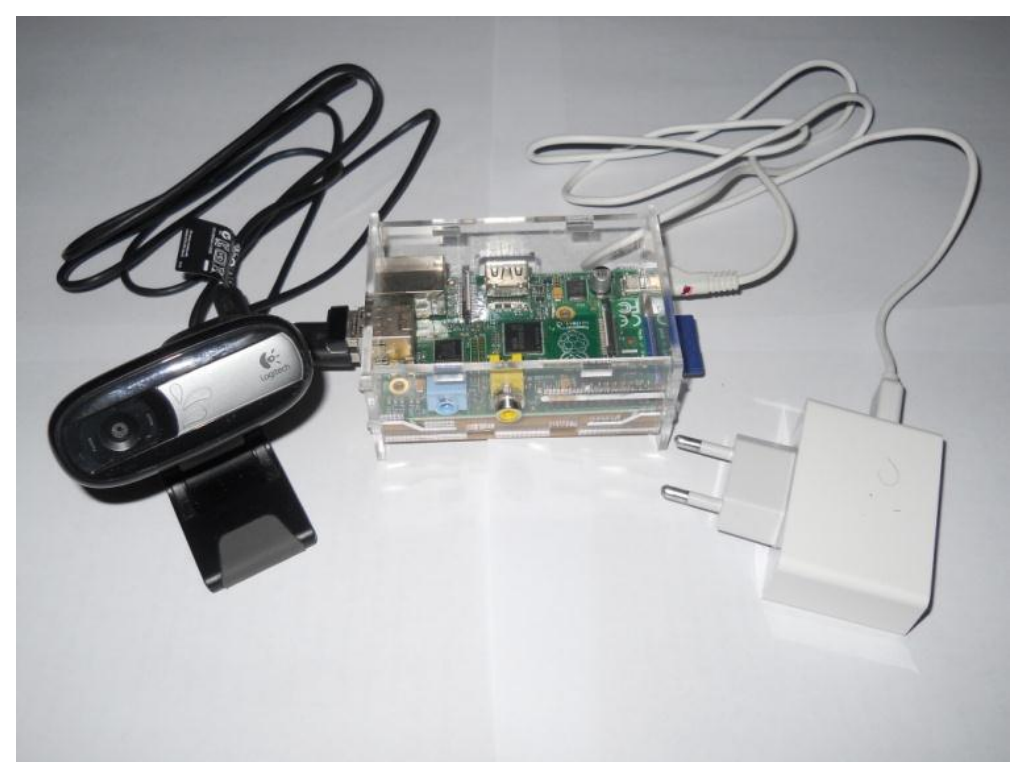

Gambar 3 Perangkat keras untuk server

\section{HASIL DAN PEMBAHASAN}

\subsection{Pengujian Sistem Secara Keseluruhan}

Pengujian sistem ini dilakukan untuk menjawab salah satu tujuan penelitian yaitu, Merancang dan membuat sistem pemantauan menggunakan server Raspberry Pi yang dapat secara otomatis merekam dan memberi peringatan melalui email jika terdeteksi gerakan di tempat yang dipantau. Keberhasilan pengujian sistem secara keseluruhan menunjukkan bahwa Raspberry Pi dapat digunakan sebagai server sistem pemantauan.

Pertama-tama sistem harus dapat berjalan begitu Raspberry Pi dinyalakan, hal ini ditujukan untuk memudahkan pengguna dalam mengoperasikan sistem. Untuk mengeksekusi

IJEIS Vol. 5, No. 1, April 2015 : 65 - 76 
motion saat startup, telah dibuat sebuah program yang akan berjalan saat Raspberry Pi start up, yaitu motionboot. Program ini akan mengeksekusi motion, sehingga secara tidak langsung motion juga akan berjalan begitu Raspberry Pi start up. Selain mengeksekusi motion, motionboot juga akan menghapus semua file berekstensi “.jpg" di direktori /etc/motion, direktori tempat menyimpan citra dan video hasil rekaman motion. Pada saat terdeteksi gerakan, motion akan mulai merekam dan semua frame yang terekam disimpan sebagai citra berekstensi “.jpg" di folder tersebut, sehingga setiap kali perekaman disimpan pula banyak citra yang bila dibiarkan lama kelamaan akan memenuhi storage dari raspberry pi, karena itu semua file citra tersebut perlu dihapus setiap kali start up. Untuk file video, sengaja tidak dihapus karena dapat dihapus setelah di upload, selain itu juga untuk menanggulangi saat jaringan internet mati, sehingga walaupun tidak berhasil diupload, file video masih tersisa di storage. Potongan program pada motionboot yang dieksekusi saat booting dapat dilihat pada Gambar 4.

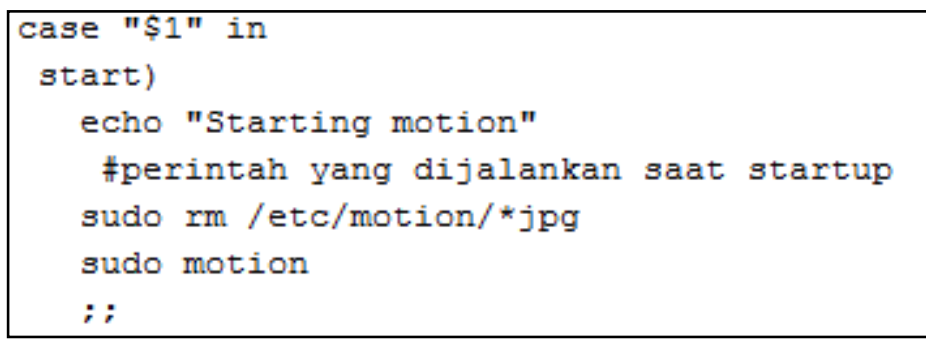

Gambar 4 Potongan program yang dieksekusi saat booting.

Untuk mengecek keberhasilan program motionboot, tinggal mengecek video streaming melalui Web browser, bila video streaming tertampil, berarti program motionboot berjalan dengan baik. Untuk melihat stream dari motion, masukkan alamat 192.168.137.3:8081 pada browser disisi klien, maka akan tertampil stream seperti pada Gambar 5. Web browser yang disarankan adalah Web browser Apple Safari, karena Apple Safari dapat menampilkan video streaming dengan baik. Web browser Mozilla Firefox, juga dapat menampilkan video streaming di awal namun lama kelamaan browser akan error, sedangkan update terbaru dari Google Chrome tidak dapat menampilkan video streaming sama sekali.

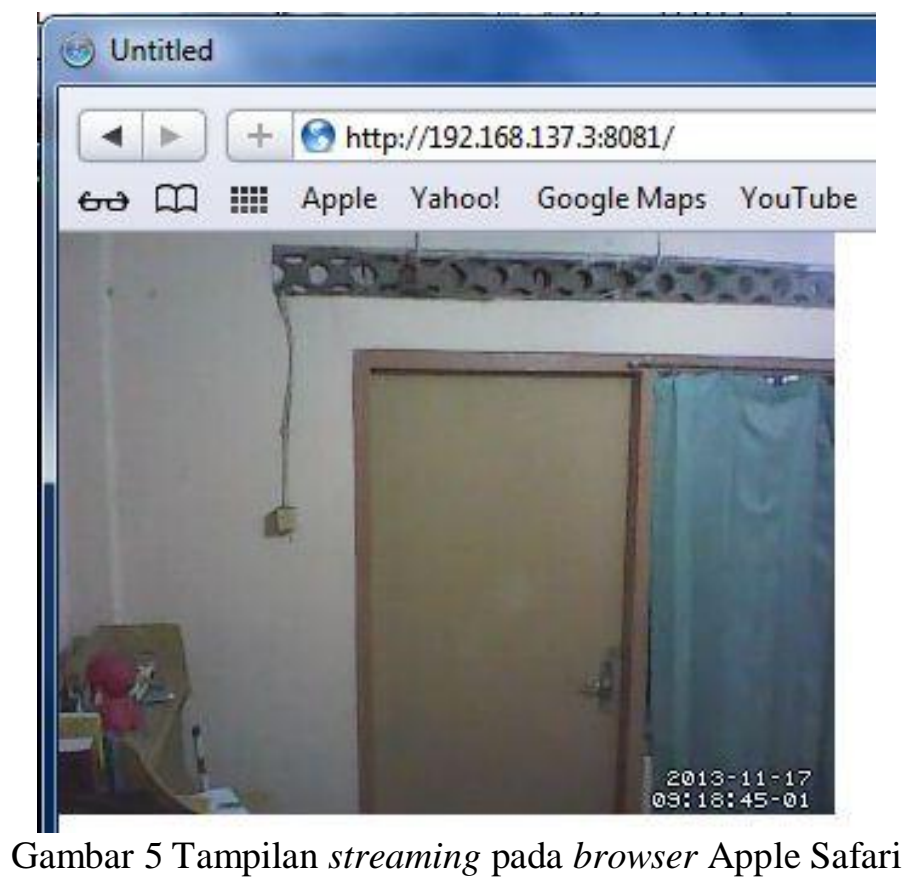


Langkah selanjutnya adalah mengecek pengirim notifikasi, notifikasi akan dikirimkan sesaat setelah terdeteksi gerakan, notifikasi dikirimkan ke email pengguna, memberitahukan bahwa telah terjadi gerakan disertai dengan link untuk video streaming dan Attachment berupa citra yang diambil saat terdetesi gerakan. Isi dari email notifikasi terlihat pada Gambar 6. pada gambar tersebut juga terlihat bahwa email tersebut membawa Attachment. Attachment tersebut berisi citra pada saat terdeteksi gerakan, namun sayangnya citra tersebut tidak dapat dilihat secara preview, jadi pengguna harus mendownload citra tersebut agar dapat melihat isinya.

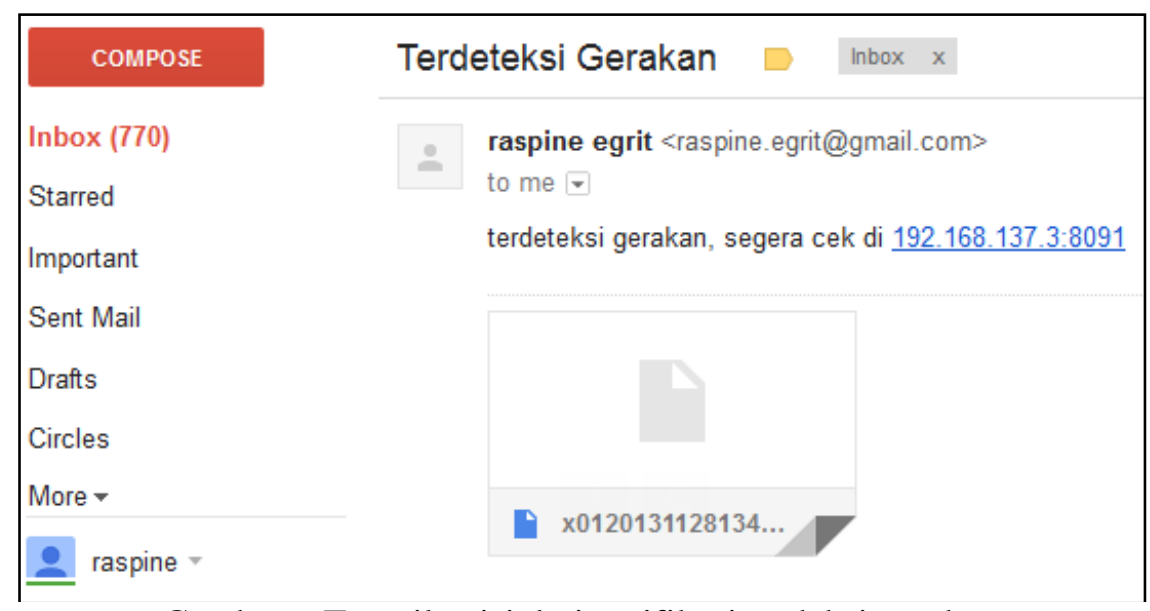

Gambar 6 Tampilan isi dari notifikasi terdeksi gerakan

Langkah berikutnya adalah mengecek pengupload video hasil rekaman motion saat terdeteksi gerakan. Video hasil rekaman tersebut akan diupload ke folder motion yang terdapat di Google Drive, setelahnya sistem akan dapat mengirim email ke pengguna untuk memberitahukan bahwa video telah selesai diupload. Isi dari email pemberitahuan bahwa video telah terupload dapat diliat pada Gambar 7. Pada gambar tersebut terlihat juga link untuk video yang baru saja diupload, jika link tersebut diklik, browser akan langsung menampilkan video yang bersangkutan, seperti yang terlihat pada Gambar 8. Dari pengujian ini dapat disimpulkan bahwa Raspberry Pi dapat digunakan sebagai server pada sistem pemantauan.

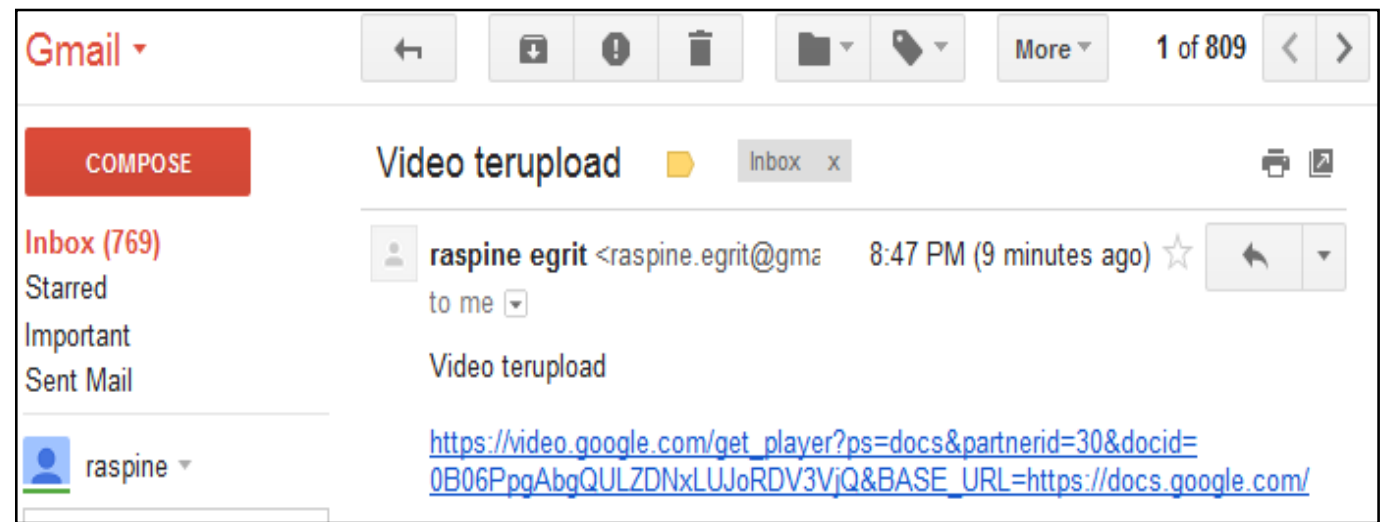

Gambar 7 Tampilan isi email pemberitahuan bahwa video telah terupload 


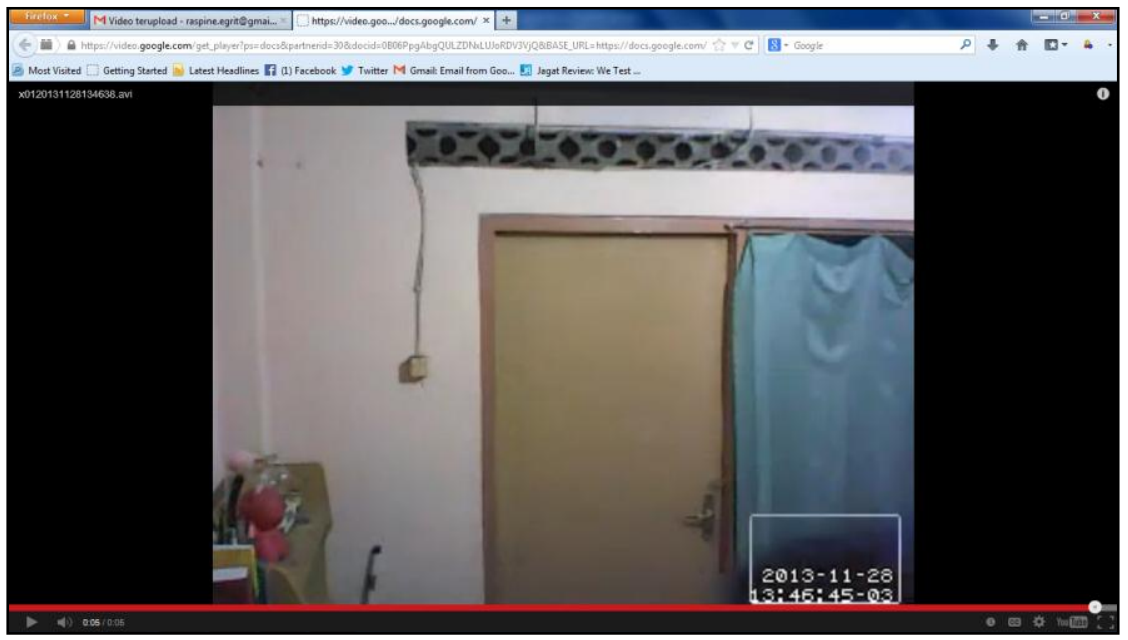

Gambar 8 Tampilan pada browser saat link pada email diklik

\subsection{Pengujian Frame size}

Komponen frame size (resolusi) menunjukkan besar bidang tampilan video yang ditampilkan pada layar. Pengujian frame size bertujuan untuk mengetahui ukuran frame size yang dapat diterima oleh sistem, dan menghasilkan video yang baik. Ukuran frame size sangat bergantung pada software maupun hardware yang digunakan oleh sistem. Hasil pengujian frame size ini dapat dilihat pada Tabel 1.

Tabel 1 Hasil pengujian frame size

\begin{tabular}{|c|c|c|}
\hline no & frame size & keterangan \\
\hline 1 & $320 \times 240$ & frame size diterima dan berjalan dengan baik \\
\hline 2 & $400 \times 300$ & error, tinggi frame (300) bukan modulo 16 \\
\hline 3 & $640 \times 480$ & frame size diterima dan berjalan dengan baik \\
\hline 4 & $640 \times 352$ & frame size diterima dan berjalan dengan baik \\
\hline 5 & $800 \times 600$ & error, tinggi frame (600) bukan modulo 16 \\
\hline 6 & $960 \times 720$ & resolusi dikonvert kembali ke 640x480 \\
\hline 7 & $1280 \times 960$ & resolusi dikonvert kembali ke 640x480 \\
\hline 8 & $1024 \times 600$ & error, tinggi frame (600) bukan modulo 16 \\
\hline
\end{tabular}

Dari hasil pengujian terlihat bahwa tidak semua frame size dapat diterima oleh sistem, frame size yang dapat diterima antara lain 320x240, 640x480 dan 640x352, ketiga frame size inilah yang nantinya akan dipakai dan diujikan. Sedangkan frame size seperti 400x300, 800x600 dan 1024x600, tidak dapat diterima oleh sistem karena komponen tinggi frame -nya bukan modulo 16. Ini sesuai dengan ketentuan dari motion yang mengharuskan komponen tinggi dan lebar dari sebuah frame adalah bilangan dengan kelipatan 16, agar sesuai dengan algoritma pendeteksian gerak. Sedangkan frame size yang lain seperti 960x720 dan 1280x960 tidak dapat diterima dan akhirnya dikonvert kembali ke ukuran 640x480, ini menunjukkan bahwa nilai frame size maksimal yang dapat diterima oleh sistem adalah 640x480. Keterbatasan ini mungkin disebabkan oleh driver atau hardwarenya, dalam hal ini Raspberry Pi. Nilai 640x480 sendiri ditentukan oleh driver, Motion memberikan perintah kepada driver untuk mengecek nilai frame size yang dimasukkan oleh user dengan perintah xioctl(s->fd, 
VIDIOC_TRY_FMT, \&s->fmt) jika nilai frame size di dukung oleh driver maka nilai frame size tersebut akan digunakan, jika tidak maka driver akan mencari nilai frame size yang sesuai.

\subsection{Pengujian Pengaruh Frame size Terhadap Frame rate}

Pada bagian ini akan dibahas pengaruh dari frame size yang digunakan terhadap frame rate pada video yang dihasilkan. Frame rate adalah jumlah bingkai gambar atau frame yang ditunjukkan setiap detik dalam membuat gambar bergerak, diwujudkan dalam satuan frames per second (fps). Makin tinggi angka fps-nya, semakin halus gambarnya. Pada pengujian ini digunakan 3 frame size yang akan dibandingkan frame rate videonya. Pengujian dilakukan pada intensitas cahaya maksimum yaitu 15 lux. Pada Tabel 2 terlihat perbedaan pada frame rate tidak terlalu besar, walau frame size berubah. Selisih antara frame rate pada frame size $320 \times 240$ dengan frame rate pada frame size 640x352 hanya 0.2 fps begitu juga selisih antara frame rate pada frame size 640x352 dengan frame rate pada frame size 640x480. Dari Tabel 2 tersebut dapat ditarik kesimpulan bahwa pengaruh perubahan frame size terhadap frame rate tidak terlalu signifikan. Frame rate pada Tabel 2 adalah frame rate maksimum yang dapat digunakan oleh sistem. Secara default frame rate yang digunakan sistem adalah frame rate yang didukung oleh Webcam, dalam hal ini 24-30 fps, namun frame rate ini tidak langsung digunakan begitu saja, pertama-tama sistem akan menyuruh driver untuk mengecek frame rate ini, dengan perintah xioctl(s->fd, VIDIOC_S_PARM, setfps), jika ternyata frame rate masukan tidak didukung oleh sistem maka driver akan memberikan nilai framerate yang dapat didukung oleh sistem. Keterbatasan ini dapat disebabkan oleh hardware (raspberry pi), atau drivernya.

Tabel 2 Hasil pengujian pengaruh frame size terhadap frame rate

\begin{tabular}{|c|c|c|c|c|}
\hline \multirow{2}{*}{ no } & \multirow{2}{*}{ intensitas cahaya (lux) } & \multicolumn{3}{|c|}{ frame rate } \\
\cline { 3 - 5 } & & $320 \times 240$ & $640 \times 480$ & $640 \times 352$ \\
\hline 1 & 15 & 6,96 & 7,93 & 6,95 \\
\hline 2 & 15 & 6,97 & 5,95 & 6,96 \\
\hline 3 & 15 & 6,97 & 5,95 & 5,96 \\
\hline 4 & 15 & 6,98 & 6,94 & 6,94 \\
\hline 5 & 15 & 6,96 & 5,95 & 6,96 \\
\hline & rata rata $=$ & 6,968 & 6,544 & 6,754 \\
\hline
\end{tabular}

\subsection{Pengujian Pengaruh Frame size Terhadap Bitrate}

Frame size yang besar membutuhkan pengolahan data yang lebih lama, karena data yang diolah semakin banyak. Pada pengujian pengaruh frame size terhadap bitrate ini ditunjukkan bitrate yang digunakan pada setiap frame size. Pada Tabel 3 diperlihatkan nilai bitrate yang berbeda-beda pada setiap frame size yang diujikan, semakin besar frame size -nya semakin besar bitratenya.

Bitrate yang ditampilkan adalah bitrate pada video hasil perekaman, sehingga video telah terkompres dan membuat bitrate video yang dibutuhkan lebih kecil daripada bitrate video sebelum dikompres (raw video). Walaupun telah terkompres perbedaan bitrate pada video dengan frame size yang berbeda tetap terlihat signifikan dan cukup memberikan gambaran tentang pengaruh framesize terhadap bitrate. Pada video dengan frame size besar dibutuhkan waktu yang lebih lama untuk diolah, seperti yang telah dibahas pada subbab 3.3 tentang pengaruh frame size terhadap frame rate, diketahui bahwa nilai frame rate kurang lebih sama,

IJEIS Vol. 5, No. 1, April 2015 : 65 - 76 
walaupun frame size nya berbeda-beda, hal ini dikarenakan nilai bitrate yang semakin membesar saat frame sizenya juga membesar, sehingga pengolahan datanya bisa menjadi lebih cepat dan menghasilkan frame rate yang tetap. Ini menunjukkan sistem dapat megimbangi kebutuhan bitrate yang semakin besar seiring semakin besarnya frame size yang digunakan.

Tabel 3 Hasil pengujian pengaruh frame size terhadap bitrate

\begin{tabular}{|c|c|c|c|c|}
\hline \multirow{2}{*}{ no } & \multirow{2}{*}{ intensitas cahaya (lux) } & \multicolumn{3}{|c|}{ bitrate $(\mathrm{kbit} / \mathrm{s})$} \\
\cline { 3 - 5 } & & $320 \times 240$ & $640 \times 480$ & $640 \times 352$ \\
\hline 1 & 15 & 402 & 533 & 529 \\
\hline 2 & 15 & 416 & 536 & 518 \\
\hline 3 & 15 & 412 & 529 & 521 \\
\hline 4 & 15 & 399 & 534 & 531 \\
\hline 5 & 15 & 452 & 517 & 518 \\
\hline & rata rata $=$ & 416,2 & 529,8 & 523,4 \\
\hline
\end{tabular}

\subsection{Pengujian Pengaruh Frame size Terhadap Deteksi Gerak}

Pada bagian ini dibahas tentang pengaruh frame size terhadap deteksi gerak. Pendeteksian gerakan pada motion dilakukan dengan membandingkan frame terbaru dengan frame acuan, bila ada perbedaan maka akan dideteksi sebagai gerakan. Semakin besar frame size videonya maka semakin lama motion harus mengolah sebuah frame untuk mendeteksi ada tidaknya gerakan dalam frame tersebut. Semakin lama sebuah frame diolah oleh motion maka akan semakin banyak frame yang tidak diikutsertakan pada rekaman dan menyebabkan durasi video hasil perekaman lebih pendek dari seharusnya. Hal ini dibuktikan dengan hasil pengujian yang ditunjukkan pada Tabel 4, dimana rata rata durasi video hasil rekaman berbeda-beda pada tiap frame size yang diujikan. Pada saat pengujian penguji membuat gerakan untuk direkam oleh motion selama 30 detik.

Tabel 4 Hasil Pengujian pengaruh frame size terhadap durasi video

\begin{tabular}{|c|c|c|c|c|}
\hline \multirow{2}{*}{ no } & \multirow{2}{*}{ intensitas cahaya (lux) } & \multicolumn{3}{|c|}{ durasi (detik) } \\
\cline { 3 - 5 } & & $320 \times 240$ & $640 \times 352$ & $640 \times 480$ \\
\hline 1 & 15 & 40 & 20 & 15 \\
\hline 2 & 15 & 39 & 21 & 19 \\
\hline 3 & 15 & 39 & 23 & 20 \\
\hline 4 & 15 & 40 & 19 & 16 \\
\hline 5 & 15 & 21 & 23 & 20 \\
\hline & rata rata $=$ & 35,8 & 21,2 & 18 \\
\hline
\end{tabular}

\subsection{Pengujian Pengaruh Intensitas Cahaya Terhadap Deteksi Gerak}

Pada pengujian ini kita dapat melihat pengaruh dari intensitas cahaya terhadap deteksi gerak dengan melihat durasi dari video yang dihasilkan. Pada pengujian ini penguji menggunakan stopwatch agar sistem merekam gerakan selama 30 detik. Namun pada video hasil rekaman, durasi video berbeda-beda, seperti yang terlihat pada Tabel 5, karena sistem 
tidak dapat mendeteksi gerakan dengan sempurna sehingga frame yang tidak terdeteksi gerakan tidak dimasukkan dalam video.

Tabel 5 Hasil pengujian pengaruh frame size terhadap durasi video pada intensitas yang bervariasi

\begin{tabular}{|c|c|c|c|c|}
\hline \multirow{2}{*}{ no } & \multirow{2}{*}{ intensitas cahaya(lux) } & \multicolumn{3}{|c|}{ Durasi(detik) } \\
\cline { 3 - 5 } & & $320 \times 240$ & $640 \times 480$ & $640 \times 352$ \\
\hline 1 & $0 \sim 1$ & 0 & 0 & 0 \\
\hline 2 & 1 & 1 & 9,4 & 10,6 \\
\hline 3 & 2 & 5,6 & 7,8 & 19,4 \\
\hline 4 & 3 & 9,2 & 15,2 & 22 \\
\hline 5 & 4 & 5,8 & 17,6 & 23,4 \\
\hline 6 & 5 & 11,8 & 18 & 22,8 \\
\hline 7 & 6 & 19,6 & 18,6 & 20,4 \\
\hline 8 & 7 & 24,6 & 17 & 22,6 \\
\hline 9 & 8 & 37,2 & 20 & 23,6 \\
\hline 10 & 9 & 36,2 & 18,4 & 23,4 \\
\hline 11 & 15 & 35,8 & 18 & 21,2 \\
\hline
\end{tabular}

Pada resolusi 320x240 dengan intensitas cahaya maksimum yaitu 15 lux, rata-rata durasi video yang dihasilkan adalah 35,8 detik, karena frame acuan yang belum terupdate sehingga masih ada obyek didalam frame acuan padahal pada kenyataannya sudah tidak ada, bila terdeteksi gerakan maka frame tersebut akan disambung dengan frame sebelumnya, bila tidak terdeteksi gerakan selama 10 detik maka event tersebut dianggap selesai. Pada Tabel 5 terlihat durasi video semakin meningkat bila intensitas cahaya semakin tinggi, ini menunjukan bahwa semakin tinggi intensitas cahayanya semakin baik pendeteksian geraknya.

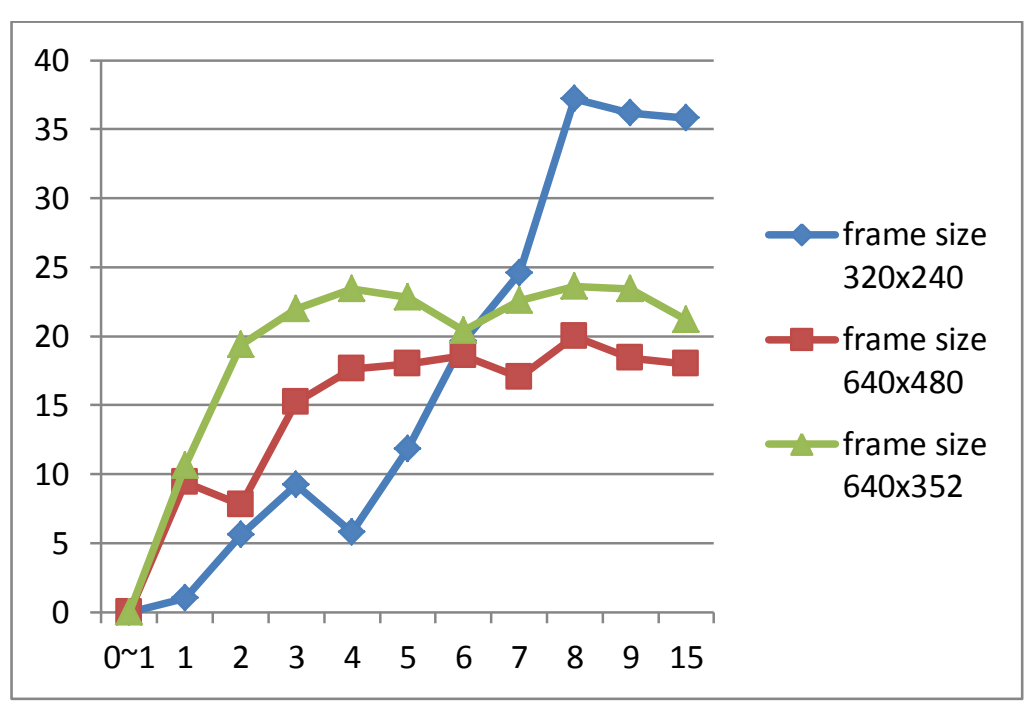

Gambar 9 Grafik hubungan antara intensitas cahaya (sumbu x) terhadap durasi video (sumbu y)

Pada pendeteksian gerakan oleh Motion, terdapat nilai threshold minimal yang harus dilewati agar selisih pada satu frame dengan frame acuan dapat dianggap sebagai gerakan. Nilai default dari threshold adalah 1500 pixel, maka dari itu selisih atau perubahan yang terdeteksi pada satu frame harus melebihi 1500 pixel agar dapat dianggap sebagai gerakan. Sehingga pada 
intensitas cahaya yang sama, dengan frame size yang lebih besar akan lebih mudah mendeteksi gerakan karena perubahan pixelnya menjadi lebih banyak. Hal ini ditunjukkan pada Tabel 5 dimana pada intensitas cahaya yang rendah, seperti 1,2,3, dan 4 lux, frame size 640x480 dan 640x352 memiliki durasi video yang lebih panjang daripada durasi video pada frame size 320x240. Hal ini juga yang menyebabkan frame size 640x480 dan 640x352 mencapai durasi yang sama dengan durasi pada intensitas cahaya maksimal pada intensitas antara 3-4 lux atau dengan kata lain mencapai durasi maksimal pada intensitas cahaya lebih dari 4 lux. Sedangkan frame size 320x240 mulai mencapai durasi maksimal pada intensitas 8 lux seperti yang ditunjukkan pada grafik pada Gambar 9. Tercapainya kondisi durasi maksimal ditunjukkan dengan kecenderungan grafik membentuk garis horizontal yang dimulai pada intensitas cahaya tertentu, 8 lux untuk frame size 320x240, 3 lux untuk frame size 640x352, dan 4 lux untuk 640x480. Pada intensitas cahaya tersebut sistem mencapai kondisi durasi maksimal yang ditandai dengan tercapainya durasi video maksimal yaitu antara 20 hingga 25 detik pada frame size 640x352 dan antara 15 hingga 20 detik pada frame size 640x480. Dari pengujian ini didapatkan kesimpulan bahwa semakin besar frame size video dari sistem maka sistem tersebut akan semakin peka terhadap gerakan, namun semakin besar frame size videonya maka semakin lama waktu yang dibutuhkan sistem untuk mengolah satu frame, dan mengakibatkan semakin banyak frame yang tidak terolah oleh sistem dan tidak masuk kedalam video.

\section{KESIMPULAN}

Dari penelitian yang telah dilakukan, telah dibuat sebuah sistem pemantauan ruangan dengan server raspberry pi yang dapat secara otomatis merekam dan memberikan notifikasi jika terdeteksi gerakan, kesimpulan yang dapat diambil dari penelitian ini adalah sebagai berikut :

1. Untuk mendapatkan video tanpa ada frame yang hilang, frame size yang digunakan adalah 320x240 dengan intensitas cahaya minimal 8 lux

2. Pengaruh perubahan frame size terhadap frame rate tidak signifikan.

3. Frame size yang lebih besar menyebabkan motion lebih peka terhadap gerakan karena jumlah perubahan pixel yang terjadi menjadi lebih banyak daripada pada frame size yang lebih kecil.

4. Intensitas minimal untuk motion hingga dapat mendeteksi gerakan adalah 1 lux pada frame size 320x240, 640x352 dan 640x480.

\section{SARAN}

1. Sistem ini masih sebatas diujikan pada jaringan WLAN. Diharapkan penelitian selanjutnya dapat ditingkatkan sehingga video streaming dapat diakses melalui internet.

2. Jika selanjutnya masih mengembangkan sistem pemantauan dengan motion, maka diharapkan dapat menggunakan lebih dari satu webcam sehingga dapat mengetahui pengaruh dari jumlah webcam terhadap kemampuan raspberry pi sebagai sistem pemantauan.

3. Penelitian selanjutnya diharapkan menggunakan program selain motion, sehingga dapat dibandingkan dengan pengujian ini. 


\section{DAFTAR PUSTAKA}

[1] Ero, J, 2009, Sistem Monitoring Berbasis Live Video Streaming Dan Dilengkapi Notifikasi SMS, Skripsi, Ilmu Komputer FMIPA UGM, Yogyakarta.

[2] Holandrio, D., 2012, Sistem Video Streaming Dengan Server Mini Personal Computer (Mini Pc) Pada Jaringan Ad-Hoc, Skripsi, Elektronika dan Instrumentasi FMIPA UGM, Yogyakarta.

[3] Lavrsen, K., 2010, Motion Guide for Motion version 3.2.12, http://www.lavrsen.dk/foswiki/bin/view/Motion/MotionGuide3x1x20, diakses pada tanggal 26 Februari 2013

[4] Al-Tayeeb, R., 2012, Motion JPEG Streaming Server, http://www.codeproject.com/Articles/371955/Motion-JPEG-Streaming-Server, diakses pada tanggal 1 Desember 2013

[5] Novasandro, R., dan Kautsar, A. E., 2009, Prinsip Kerja Protokol - Protokol Electronic Mail, Jurusan Teknik Elektro Fakultas Teknik, Universitas Gadjah Mada

IJEIS Vol. 5, No. 1, April $2015: 65$ - 76 